\title{
Microarchaeology, Materiality and Social Practice
}

\author{
Per Cornell \& Fredrik Fahlander
}

\begin{abstract}
In this paper we propose an operative social theory that eliminates the need for a pre-defined regional context or spatio-temporal social entities like social system, culture, society or ethnic group. The archaeological object in a microarchaeological approach is not a closed and homogeneous social totality, but rather the structurating practices, the regulative actions operating in a field of humans and things. In order to address these issues more systematically, we discuss social action, materialities and the constitution of archaeological evidence. Sartre's concept of serial action implies that materialities and social agency are integrated elements in the structuration process. We suggest that such patterns of action can be partially retrieved from the fragmented material evidence studied by the archaeologist.
\end{abstract}

Per Cornell \& Fredrik Fahlander, Department of archaeology, University of Gothenburg, Box 200, SE-405 30 Göteborg, Sweden.

Key words: agency, social practice, Sartre, materialities, mortuary practices, landscape, region, NW Argentina, Arcadia

A classic topic for archaeology has been to discuss the extension and genealogy of fixed, large-scale, social entities (cultures, ethnic or regional groups), as understood in material assemblages. Some sort of sociocultural unit has always been regarded as a natural and logical point of departure for archaeological analysis. Working in this tradition implies using information from spatially separate areas to reconstruct the cosmology and typical practice of a social group during a certain time-span (i.e., the culture). The main idea is thus to combine fragmented and incomplete material evidence from different regions to reconstruct virtual social entities (e.g., TRB-culture or a Viking society).

This tradition is represented in both processual and post-processual archaeology. Processual archaeologists have tried to establish functional traits that define each type of social form, whereas post-processualists have been more interested in the cosmology or symbolic schemes. In contrast to processual archaeology, the post processualist stresses the plural and multivocal understanding of meaning (Shanks \& Tilley 1987). More recently, some archaeologists have argued that sociocultural systems are open and populated by knowledgeable heterogeneous agents (e.g., Gero 2000). Still, many archaeologists seem to presuppose that individuals within given social entities share a common interpretative horizon, in which social action has meaning and can be understood. This latter view contradicts, however, the image of open systems, and this theoretical problem cannot be solved by ad hoc arguments. In recent social theory, the 
whole idea of such social entities has been problematised, pointing to multivocality and the problems involved in defining social entities spatially, temporally or socially (e.g., Barth 1992:19). But is it possible to address action if we discard any concept implying the existence of social or cultural units? It is certainly a great challenge to approach social action without such a conceptual framework, but it might well be worth the effort. We argue that a microarchaeological approach that examines structurating practices and structurating positivities across time and space allows for such an analysis. By focusing on executed actions, or rather, the material traces of action, there is no need to confine analysis to the limits of a given social formation, ecosystem or spatially defined region. To enable such an analysis, we need to explore the constitution of social action and how action is related to the archaeological record. We begin by discussing the socialness of things, that is, the importance of materialities in social action, followed by a discussion on the regularity and the collective character of social action.

\section{SOCIAL PRACTICE AND THE DISOBEDIENT OBJECT}

Things are divorced from their names. They are there, grotesque, headstrong, gigantic and it seems ridiculous to call them [something] or say anything at all about them: I am in the midst of things, nameless things. Alone, without words, defenceless, they surround me, are beneath me, behind me, above me (Sartre, Nausea 1959 [1938]:169)

These awful things: this hatred of things was a characteristic trait of modernism but also of many brands of romantic and neo-conservative movements. The existential Sartre cries out his hate in books like Nausea. Things are bad; they are obstacles complicating human existence and, what is worse, they escape determination. Sartre's outcry is very much a popular version of what many philosophers and social scientists have claimed; social practice and social interaction is a sphere exclusively for active humans, not for the cultural artefacts, for the silent monuments or for the animals of the natural world. Processual archaeology largely adopted this notion. Social action was seen as regulated by norms of the (ideational) cultural system. Thus, the idea of materialities as a mere mirror of social and cultural systems was close at hand, and this notion came to dominate archaeological debate. Post-processual archaeology criticised this approach and opened up for a more dynamic way of analysing materialities and social life. Recently the 'socialness of things' has been stressed in various strands of social theory and particularly in archaeology (e.g., Latour 1992, 1993; Riggins 1994; Andrén 1997; Schiffer 1999; Graves-Brown 2000; Cornell \& Fahlander 2002). These attempts at incorporating things, artefacts and aspects of the environment, as being social actants in the social process, range from symbolic to hard data analysis. Most studies only address particular aspects of materialities, and they seldom dare to propose a more general approach.

In order to develop alternative approaches, we can be inspired by Jean-Paul Sartre and in particular his later writings (1960), but also by Bruno Latour and his network 
theory $(1993,1999)$. Sartre shows us that performed social practice constitutes a link between being and materialities. In this way we are not confined to strictly functional or symbolic interpretative schemes. Sartre introduced the concept of social series (repeated semi-conscious action), which can interestingly enough be articulated to Latour's notion of actants (vehicles for action). As pointed out by Latour, an actant performing given identical actions may well be human or non-human. A door may be opened by the action of turning the doorknob, or by highly sophisticated sensors. Smoke detectors are another example. They may well be installed in environments where nobody accepts the ethical ideas they imply. Still, the sound of the alarm is an impetus to follow the rule. Materialities may well act, so to speak, from a distance in space and time, as a lagged or delayed effect as termed by Roy Bhaskar (1993:140141), and at times not even in line with the intentions of the constructor. The nuclear disaster at Chernobyl caused measurable traces in faraway places; though this is an extreme example, large-scale effects of human action on the environment can be archaeologically demonstrated (cf. McIntosh, Tainter \& McIntosh 2000).

Actants may operate in different ways: as a prolonged arm of an individual; replacing the human subject; or as to enable, or constrain, certain tasks. An illustrative example of how material culture can unintentionally interact in the social process is found in the archaeology of Michel Foucault. For instance, in The Birth of the Clinic (1963) he argues that the very existence of separated and isolated leprosariums in early 16thcentury Europe played an active part in the process of discerning the mad as a social category. The mere material existence of leprosariums may have stimulated, if not evoked, that process by their very presence.

Material remains constitute, in a sense, mute objects, since they do not address us directly. Sartre made an important point in Nausea when he pointed to the way in which material objects escape naming. The object will not accept being named. The information residing in the object is vast, but there is no means of naming that will accurately cover this potential. At the same time, it is this multiple information residing in the object that makes archaeology possible.

\section{SERIAL COLLECTIVITY, MATERIALITIES AND SOCIAL PRACTICE}

It is somewhat symptomatic that it is the later works of Sartre (that is, the man who hated things) in which we find elements for a social theory that integrates materialities and human action (Sartre 1960). Sartre points to the 'real' existence of materialities. Things constrain or enable us in our day-to-day social activities and interact in the making of our mental images. Sartre's objective was to grasp a given social totality, the resultant emerging from a number of social factors, without thereby excluding either materialities or individual action. In his theory, materialities and human subjects interact dialectically; it is neither a matter of autonomous individuals with a free will, nor structural dopes confined by ecology or defined by materialities. Sartre elegantly sketches a picture of the complex relations of the microsituation and the more general social structures involved. In this sense, he is very much a predecessor; we find similar arguments in the works of Bourdieu (1980), in the structuration theory of Giddens 
(1984), and even in Bhaskar's (1994) dialectics of liberation, but these latter thinkers lack the explicit material dimension in their social analysis. Indeed, the multiplicity of social integration cannot be reduced to atomised objects, or simple functional system theories. Sartre saw social integration as a process of totalisation, a process (not an entitity) of interiorisation of multiplicities. This process is, in a sense, an integration of the possible social diversity or difference. As stressed by Gero (2000), the subject is a heterogeneous entity. To argue that the social subject is heterogeneous is, however, not to state that there is no social regularity or repetitiveness. Action may be conscious and intentional, but several studies (cf. e.g., Goffman 1967) have indicated that day-to-day social practice is largely semi-conscious or non-conscious. Further, unacknowledged conditions, unconscious motivation, tacit skills and unintended consequences make social process opaque to social agents (Bhaskar 1994:94-95). Action corresponds to a whole set of social phenomena and occurs in a whole set of social situations, and this must be kept in mind when applying the concept. Moreover, there are always regularities and patterns in the social process, often centred on materialities. To illustrate his argument, Sartre discussed people waiting at a bus stop. These individuals are not integrated as a group in a strict sense, they are rather solitaries, united by a common pattern of action; they are waiting for a bus, to be transported somewhere. Sartre calls this kind of pattern a series. Marion Young has applied this line of thought and summarises the argument as follows.

Serial collectivity, according to Sartre, is precisely the obverse of the mutual identification of the group. Each goes about his or her business /.../Individuals in the series are fungible; while not identical, from the point of view of the social practices and objects that generate the series, the individuals could be in one another's place. (Young 1997:24)

People waiting for the bus form a series; they have momentarily a common identity, but their intentions may differ completely. The participation in such a short-lived series implies that the plurality of individuals, the differences between them, is momentarily of less significance. The very existence of public transportation, like busses, constitutes the node on which this particular series is based. This is, however, not the only reason for which these individuals wait at the bus stop. The fact that they are waiting at the same bus stop is related to a diversity of factors, which may include level of income, sex, ethnicity etc. People waiting at a bus stop have a kind of intention: to take the bus in order to arrive some place. But in many cases this is only partly intentional. If they intend to go to work, it may just be a repeated way to act. Getting up in the morning, eating breakfast, and taking the bus to work are routine actions, and the intention is seldom very clear or well defined by the actors participating in the process. People often have limited knowledge of the implications of their own doings. For instance, William Rathje's well-known garbage project, analysing domestic refuse from American households, has shown that people often deliberately or unconsciously give incomplete or erroneous accounts of their actions (Rathje \& Murphy 1992:67). Thus, serial action may be more common than we think. Individuals may in many situations act and think 
as solitaries, but they nevertheless reproduce patterns according to general social and material conditions. The series can be related to the concept of the actant, as discussed by Latour. In a series, humans and material artefacts interact and may even be interchanged, that is, they constitute true actants. It is in the series that the human-artefact relation may reach a point at which the boundary between them becomes blurred and fuzzy.

The serial perspective has been proven useful when applied to social problems. At a more general level, the industrial worker or the office clerk can be considered a serial phenomenon. Young has also recently argued that 'women' are better seen as a serial phenomenon than a social category. It is obvious, as argued in post-structural and post-colonial debate, that women of different social classes, in different parts of the world, cannot be regarded as a homogeneous group. Young argues that most women are constrained to certain situations, and restricted to interaction with certain particular materialities, when living in a patriarchal order. For instance, it would not be surprising to find many women in the bus queue, while their husbands dispose the family car.

Sartre uses the term series rather than social category or group. The term 'group' is reserved for another social phenomenon: the active, intentionally organised group. In a group, each individual takes an 'oath' upon entering and works systematically to achieve a given common purpose. A group may try to change a social or political situation, and most of Sartre's examples refer to political action. But a group may also strengthen a given institutionalised structure, reinforce it. It is common that a group utilizes given serial phenomena. For instance, Sartre discusses how the German Naziparty used a serial phenomenon, European anti-Semitism, by aggrandizing it and adapting it to specific political intentions.

Sartre's conceptualisation of series and groups is interesting and may turn out to be constructive in developing arguments on materiality and social practice. Instead of working with large macroconcepts we may define particular serial and group phenomena and study their correlation and interrelation. In order to describe the workings of series and groups, and how series are related to each other and to groups, we will introduce a metaphor: that of fibres, threads and ropes.

\section{BEYOND SOCIAL SYSTEMS: FIBRES, THREADS AND ROPES}

Sartre's concept of seriality helps to disintegrate the modernist ideas of social categories as homogeneous entities by arguing that series are formed by social practice in relation to materialities. Traditional social analysis in archaeology was made on given macroframes, such as a time-period or a culture (e.g., the Neolithic or the La Téne culture). This implied a set of a priori statements about simultaneous change in different aspects of materialities and social life. Such conceptualisations complicate or prevent the analysis of social change and often the study of internal variability within such timespace units (cf. Barrett 2000).

Another problem is that general social theory discussed regulated social practice as the effects of given high-level abstractions, such as politics, economics, religion, cosmology or ideology. To give an example, Clarke (1968:185) presented a diagram 
containing the elementary subsystems of society or culture. His list included economic, religious, social, psychological and material subsystems. But the social world is diverse and made up of many different elements, not all of which actually integrate. Further, it cannot be taken for granted that all social forms have, say, a distinct entity called religion, as separated from economy. This is not an issue unique to processual archaeology; the same problem is also inherent in later post-processual and interpretative archaeologies, as well as in social theory in general. These modernist constructions were created at a time when social practice was considered very much a commonsense issue in terms of rational economic theory. It is a bit surprising that such stiff global concepts are still regarded as valid, as they seem to create more problems than they help to solve. There is certainly a need for more open and operative concepts related to particular instances of social practice.

The art-historian George Kubler (1962: 127-128) made a similar point when he criticised art-history for working only from textual references, that is, traditional hermeneutical iconology. Following Kubler's line of argument, it is not possible to explain social practice only by reference to closed worlds of discourse or 'symbolic schemes'. There is no closed structural 'language' or collective representations to explain all action (cf. Cornell 2000). Social interaction always involves parallel phenomena, ruptures and contradictions, which thus open up structures and allow us to partially break codes.

To illustrate a more flexible way to perceive complex relations between different facets of a social situation, which may also prove more operational, we suggest the metaphor of fibres and threads. Wittgenstein (1953:\$67; cf. Kubler 1962: 122) applied this metaphor in his discussion of 'family resemblances'. Instead of letting resemblances form absolute groups, he perceives the similarity between attributes in terms of fibres and threads. A thread is made up of separate fibres of different lengths wrapped over each other, and each of them does not necessarily extend all through the thread. We argue that this way of thinking provides an operative approach to social practice.

An example of a fibre in a 'social thread' may be a specific structurating practice of a traditional way of making and using pots, or a way of organising and using a building. As an illustration, the repeated pattern seen in house construction at the Pichao site (STucTav5) in north-west Argentina corresponds to a social practice, a serial phenomenon. The major part of the site is dated to the $14^{\text {th }}-16^{\text {th }}$ centuries, while there is a separate settlement from the $16^{\text {th }}-17^{\text {th }}$ centuries. The densely inhabited part of the site covers more than 100 ha. At this site, pre-Hispanic social units consisted of a large rectangular building with a set of smaller attached buildings. Within this pattern there is rampant variation, attesting for social structuration to work (fig. 1). The area outside of these buildings was not generally used for activities that can be defined as domestic. These entities, a particular kind of domestic units, can be discussed and analysed in different ways, with particular reference to patterns of action in the construction and use of the buildings. To mention just one example, the distribution of ceramics demonstrates recurrent patterning within these units (Cornell 1993; Cornell et al. ms.; Cornell \& Fahlander 2002). 


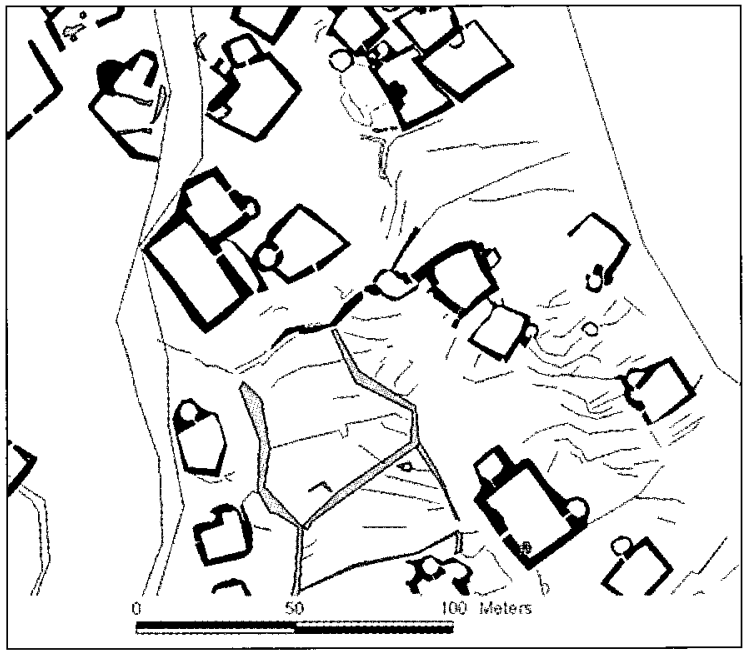

Fig 1. Section from site map of Pichao (STucTav5), NW Argentina (from Cornell et al. 2001). Map produced by Per Cornell, Leif Häggström, Ana Vega Caro and Bengt Westergaard.
Structurating practice and social positivities

The metaphor of fibres and threads can be extended over longer time-periods by having the threads make up ropes that meander through time and space. While structurating practice is relatively dynamic, it is to some extent constituted by elements that are difficult to alter, seemingly immutable structurating positivities. These are more general social phenomena, which may transcend social practices. Structurating positivities may or may not be materialised or consciously recognised, but they often operate unspoken and unthought. A simple example is the bipolar division of

sex/gender that is a prevailing factor in most contemporary societies. This principle operates on unconscious, semi-conscious and conscious levels, but it is inherent in most social practices as well as in the process of building self-identity. Some would argue, based on pseudo-evolutionary arguments, that this division is a natural principle, but as many feminists have argued, it is very much a cultural construct. As a structurating positivity, this particular facet of social life is closely related to social practice. For instance, Judith Butler has argued that our ideas of gender are largely a matter of clusters of structurating practices; that is, performance and agency 'typical' for the two sexes (Butler 1990). If, however, the structurating practices attributed to sex/gender should dissolve or disintegrate, it would be hard to sustain a generalised patriarchal order. These practices are directly related to materialities, as pointed out in the example of the bus queue, not to mention particular attributes like dress and personal items.

The relation capitalist-worker is another example of a structurating positivity. This particular type of interrelation appears in different contexts over a long time-span. Though some basic patterns in interrelations remain more or less the same, there is, nevertheless, substantial social dynamics. The structurating positivity operates on different sets of social structuration and, thus, in different fibres and threads. While the concept of structurating positivity lies, in a sense, close to that of longue durée of the French Annales school, the interrelation of fibres, threads and ropes creates a potential for dynamics beyond the longue durée. The longue durée defines phenomena that remain static, and its continuity is the most central issue. In the framework presented here, the interrelation between different fibres and threads is the key; and change in these patterns creates dynamics. Bhaskar pointed to this, though he limited his discussion 
to the presence of the past in the present. He illustrates intersecting and overlapping space-time phenomena by discussing "the amazing and putatively contradictory juxtaposition or condensation of differentially sedimented rhythmics one can find in a city like Los Angeles or New Delhi, where temples, mosques, traditions, religious rites, weddings, inter-caste conflict, electric cables, motor cars, televisions sets, rickshaws, scavengers and disposable cans coalesce in a locale" (Bhaskar 1993:55).

An archaeological illustration of a serial phenomenon is the emergence of the citystate in Iron Age Greece. The concept of the city-state can be regarded as a particular structurating positivity, linked to a rope or cluster of structurating practices. The social process from aristocracy to citizenship is complicated, involving the intentional efforts and resistance of different social groups but also the effects of certain sociohistorical and material conditions. Morris (1987) has produced an interesting study that discusses this process, based on the material evidence from burials. Morris argues that a first attempt towards the city-state was in process around 750 B.C. but failed for various reasons; the fibres involved could not sustain a cluster that could form such a rope. For a number of years the process ceased, and the social structure returned to the old order, only to be re-initiated and finally established with the reform of Cleisthenes in the sixth century B.C. Morris' study is traditional in the sense that he views the process as a competition between two social groups, kakoi and agathoi. It would probably be more interesting to try to identify, on a broader level, the social practices involved in this process at large, rather than only discussing the power relations between two social groups. From the perspective of fibres and threads, the factors (fibres) involved in this process are many, but it seems evident that some lacked or were perhaps inconsistent with others in the early phase. Perhaps others replaced them at a later stage. It is important here that there is no strict teleology in the process (the extent and composition of the thread); the process might have taken other directions.

In some cases, the relation between given threads may trigger a set of transformations of the type discussed by Colin Renfrew (1984) in terms of a multiplier effect, a term borrowed from the economist John Meynard Keynes. Some threads may be neutral to each other, while some threads, given the context, may appear as singular and different, resembling the concept of the symptom as used by Slavoj Zizek (1989). Finally, different threads may enter into conflict; it may be a directly and immediately destructive conflict (cf. Adorno 1966), that causes general breakdown, or, possibly, a different kind of conflict that may lead to a paradoxically appearing constructive resultant (cf. Bhaskar 1993, 1994). It is of great importance to stress that, in the latter case, the new resultant is not a simple cancellation of contradiction. The absence of a specific element (fibre) may also be of analytical importance, as discussed by Bhaskar (1993:158-159). Still, this latter point is a tricky problem, since absence is only 'visible' by its presence in other (relevant) contexts. Yet another problem, which we will not discuss in this article though it is an important issue, is the possibility of hierarchisation of fibres and threads, that is, the dominance of some over others in specific historical circumstances.

Thus, to conclude this section, we can assert that to make up a rope, some structurating fibres and threads need, at least momentarily, to correlate: otherwise the thread 
would dissolve. However, no social formation is so regular that we would expect to find a perfect match of fibres and threads. On the contrary, we might expect to find that many of them are inconsistent and hence do not form a coherent general cosmology or social structure. This non-coherence is partly explained by the time-lag but may also result from the social dynamic in itself. As mentioned above, Zizek (1989, 2000) has argued interestingly on this issue. He postulates that no ideology, cosmology or theoretical construct is throughout consistent. There is always something that does not fit with the general picture: the exception to the rule. Still, the relation among different fibres, threads and ropes is a key point. A cluster is not a monolith; they often split up or separate a particular thread or fibre. New elements may replace a fibre or a thread. What is linked to what and the relations among the elements is of great relevance.

It is important to note, once again, that structurating practices and positivities are not confined within social totalities like 'religion' or to a specific culture/society, nor are they necessarily restricted to a spatial or ecological area. Arguing by the metaphor of fibres and threads will thus lead us to question, in a very basic sense, cultural and ethnic entities as well as spatial concepts (e.g., region), which are often operative as study objects in archaeology and anthropology. The revisionist critique in social anthropology has convincingly argued on the difficulties of maintaining such a formalised view of social affinity and spatial organisation (Leach 1989; Gellner 1995; Fahlander 2001). The metaphor of fibres and threads (structurating practices and positivities) is an open yet operative perspective that fits both social analyses on the microlevel as well as more general macroaspects. We do not need to entirely abandon globalising concepts such as culture or ethnic group, but we must recognise their lack of operability and their unsuitability as objects of study. However, global nomenclature is often needed in general discussions, and to avoid confusion we can use the term social formations in order to describe certain (blurred and fuzzy) time-space 'clusters' of structurating practice and structurating positivities.

\section{SITUATIONISM AND MICROARCHAEOLOGY: FRAMING THE SOCIAL}

As stressed above, the distribution of particular elements of social practice need not follow the frames of political systems or ethnic entities. Thus, the archaeologist ought to avoid a priori definitions of cultures or regional networks, since these may block our ability to grasp the complexity and dynamics of social practice.

When addressing social phenomena it is often a good choice to start at a microlevel, try to identify seriality, elements of fibres and threads. As discussed above, the initiation and constitution of social practice is complex: sometimes it is intentional, sometimes it is carried out by routine or simply subconsciously performed. Moreover, the effect of an act is always to some extent unpredictable: it may be successful, but it may just as likely fail. Social action is also frequently misunderstood by others, or may have unintended consequences far beyond the realm of the agents involved (Fahlander 2001:97ff). The diversity of social practices, initiated by individual intentions, constrained or enabled by materialities, social rules and regulations, cannot be grasped within any single theory. Further, in archaeology we will only occasionally be able to 
define what sort of action we are dealing with. It would be a bit presumptuous to believe that we can account for all actions, or all types of actions, in prehistory.

In his situationist analysis, Sartre focuses on the serial, that is, regulative, aspects of social life, or in our terms, structurating practices. These are not to be understood as just particular regulated, recurrent activities of institutionalised or ritualised kind. There are structurating aspects of most social practices, though the degree of and the relation to generality varies. Traditionally, this problem is often referred to as a continuum between the individual intention and general structural forces. This particular question is complex, and it involves matters of scale and points of reference that cannot be discussed in detail here (but see Collins 1981; Koerner \& Gassón 2001:178-186; Fahlander 2001:14-30). Transferring dichotomies to continuous scales, dualities, or circles has proven to be very difficult in social analysis (e.g., Archer 1982). We argue that social practice, the performed activities of a particular situation, is, in a sense, $a$ mediation between these poles. Social practice is in different respects a result of the properties of the particular situation, but these cannot be seen as necessarily unique as they also include traditions, institutionalised power relations and other aspects of the 'outside' world.

In order to discuss social practice we need to be pretty specific to avoid empty generalization. One promising way to address particular issues without losing sight of the general, is to apply analytical 'frames' (e.g., Goffman 1974; cf. the microhistory of Levi 1991). The social situation is a concept dealing with everyday social activities and focusing on how social interaction is performed, experienced and regulated. It is an analytical frame limited by the number of agents, space and time (Collins 1981). The situation is thus not a separate event analysed by its specific properties: action is always related to the constraints and possibilities of more general structurating positivities. Addressing the social situation does not mean restricting analysis to an idiographic quest for the historically specific. Rather, the situation is a frame in which we can identify specific patterns of social practice and their interrelations, to be searched for elsewhere in other case studies. To take one example, particular arrangements of house-groups adapted to a specific type of domestic unit may often be identified at specific locations, and the extent of repetitiveness may be analysed when different microsituations are compared. With such an approach, there is no need to define a 'culture' or an 'ethnic group' in general terms. Rather, specific patterns identified at a microlevel may be searched for throughout broad spatial areas. Different social phenomena are often distributed in different ways across time and space, and to establish pre-defined areas may cause us to oversimplify and make us insensitive to variability. Viewing the social through the metaphor of fibres and threads, recognising the relation between action and materialities, and the structurating relation between the particular and the general, leads us to an operative approach: a microarchaeology.

\section{A microarchaeology of locales}

Contrary to traditional archaeological practice, the microarchaeological perspective departs from the result of performed practices of the particular to infer the general. A 
particular combination of practices performed within a locale can be seen as an indication of a thread. Different combinations of threads, clusters or ropes are likely to be present across time and space. Woven in different ways, the same fibre may occur in different threads. But some combinations may well be extended over large time and space frames. In the extension of fibres and threads, that is, structurating practice and positivities, physical or general social barriers do not have given roles. Rather than starting from a priori spatial or social units, we can search for particular fibres, threads and ropes across time and space. There are most certainly major integrative forces; political systems like empires or chiefdoms are illustrative examples. But the political system is merely a group of fibres; it always co-exists with other social phenomena, and these fibres and threads may cluster around the political system, but they can never be sufficiently explained by referring only to the said system. To what extent the political system permeates social life varies considerably, and its dominance in each area or locality cannot be taken for granted a priori (cf. e.g., Alcock 1993).

Thus, in order to create an operative framework for archaeological analysis, we suggest using the spatial concept of the locale. The locale is an archaeological unit, which may have no relation to prehistoric entities whatsoever. Locale simply stands for a certain area with some relevance to the individuals situated within its frames. It does not necessarily have to be limited by natural elements or social/political borders; a locale is a locale because it is used by a series (or group) of people. The boundaries of a locale are not necessarily based only on the world-view of the actors operating in it. It is rather a small analytical unit, selected and demarcated by the archaeologist, in order to identify structurating practices. It can be argued that an analysis of an individual locale is a traditional approach to archaeology. Particularly in rescue archaeology, certain areas are traditionally being excavated and accounted for as separate sites. This way of doing archaeology has been extensively criticised, especially since bits and pieces of information do not give us a full picture of a time-period in a certain area. For instance Lewis Binford, in his ethnoarchaeological analysis of the Nunamiut (1978), pointed at the spatial mobility of hunter-gatherers. To fully understand their way of life, he argued, the study of one settlement was not sufficient. In some cases a site was populated during a short time of the year in order to perform particular activities, such as for using the hunting stand or areas used for the preparation of skins. Similar arguments appear frequently in different contexts. Richard Bradley (1995) has applied a similar perspective in a critical evaluation of his previous research on mortuary practices. He reached the conclusion that an analysis of a single cemetery could never sufficiently account for the whole social variability of a region or a social formation. People of different status, for example, may have been buried at different places, and working in only one locality will cause us to miss this important aspect. Bradley thus suggests a regional approach for mortuary studies. However, there are some setbacks in this argument.

Certainly, as the above examples indicate, humans are almost always involved in activities transcending a particular locale. But this is not a problem regarding microarchaeology. A key problem with both Binford's and Bradley's arguments is that they 
still relate their analysis to imagined total entities like culture or society. In Bradley's case, he seems to believe that the way in which a particular society deals with its dead could tell us something about the social structure in general terms. If a whole class or social category were missing in the analysis, because they were treated differently or buried elsewhere, it would thus logically, so to speak, (following the presupposition of social structure) certainly have a great impact on the interpretation. But if the social structure is not a homogeneous or monolithic thing but rather constituted by a series of elements, of which only some are directly interrelated, the problem takes another form. Another problem with Bradley's argument is the question of scale. There is no fixed and perfect geographical frame for a given analysis: we can always make it a bit larger and incorporate new traits, which may alter the picture. Microarchaeology starts from the information given at certain localities. Based on this, patterns can be searched for elsewhere, and particular fibres, threads and ropes and their interrelations can be analysed. In microarchaeology we identify repeated patterning in a given locale; the spatial distribution across wider areas is certainly of outmost interest, but a quest for such patterning ought to avoid a priori defined locales or regions.

The principal aim of a microarchaeological investigation is to analyse and extract structurating elements in the distributions and properties of materialities at a specific locale, and to search for patterning between locales; it is not to make narratives of world-views and typical day-to-day activities. John Barrett has interestingly enough proposed that archaeology should try to understand what given material conditions and historical situations give in terms of the possibilities for being human (Barrett 1994,2001 ). This seems to be a promising approach, a kind of systematic narrative. But the precondition is that the material culture has been objectified and defined to some extent, and that the historical situation is at least partly understood. We believe that, though this is not the only aim of a situated archaeology, microarchaeology can provide good materials for the construction of narratives.

\section{SOCIAL EVENTS AND MATERIAL TRACES}

There are ways of approaching the mute material available to the archaeologist, since it exhibits recurrence and patterning. As stressed by the semiologist Molino (1992), the archaeologist must try to define what part of this patterning can be ascribed to social practice, that is, make a critical analysis of the evidence. Thus, the analytical process contains three central elements, namely identification of objects and their properties, relating objects (including their properties), and defining recurrence. In order to define human action, the concept of operative chain as introduced by André Leroi-Gourhan (cf. Dobres 2000), or the Marxist concept of labour process, may be useful. Still, the social content of this action is a key point, and in defining the variability of the social, the use of social models or, as we prefer to call them, fictions, is of great help. Fictions must be seen as analytical tools; they can hardly be subjected to a strict test. Rather, they help us to structure our argument, and they make the relation between the evidence and our argument easier to assess. It is important to use the multiple information content in the object, to avoid 'killing' the object by all too narrow 
classificatory and exclusive schemes (Ørskov 1966, 1972). It may be useful to try to keep objects 'alive', as several distinct aspects may turn out to be of relevance in a broader perspective. When defining repeated social chains of action, the archaeologist may identify clusters of action, which may be of different order. Such clusters are of outmost importance in archaeological analysis. The farmstead or the factory may constitute such clusters, but clusters may also be less stable or used only occasionally, as for example a hunting stand, as discussed by Lewis Binford (1983) in his classic studies of the Nunamiut. The relation between different clusters (of the same or different order) is the focus of dynamic social analysis in archaeology.

To illustrate the microarchaeological approach, we will briefly discuss aspects of burial analysis in relation to some examples. The Saxe/Binford approach to mortuary remains tended to defend an idea of material culture as a mirror of social structure (e.g., Binford 1971; Saxe 1970), while post-processualists stressed the political dimension, i.e. the internment as a conscious political act (e.g., Parker-Pearson 1982), or the symbolic and ritual aspects of mortuary practices (e.g., Pader 1982). In the last decade various phenomenological perspectives have been popular, emphasising issues of ethics, emotions and personal experience (e.g., Tilley 1994). In our view, none of these approaches is in itself satisfactory. Mortuary practice is a social practice and as such often repetitive, and the possible political variation relatively limited. Burial practices are very much regulated as structurating practices, although with some accepted variations. What is of importance is that a microarchaeological study of burials is the study of mortuary practices, not necessarily a study of the deceased individuals. It is rather more interesting to search for and define particular types of correlation between different types of social practice. In the frame of microarchaeology it is of little consequence whether or not these actions should be termed religious or symbolical. Special treatment of the dead certainly implies some kind of ideas concerning death, but whether or not they constitute a religion or a cosmology cannot be defined solely by the archaeological remains in the cemetery. We argue that mortuary practices are social phenomena, and that they can be analysed as such. Whether or not the thread of mortuary practices relates to a thread defined as religion must be discussed in each individual case, if this problem is defined as relevant.

\section{Mortuary practices as structurating practices: some examples}

The series of actions carried out in a cemetery can be reconstructed in an interesting way by archaeologists. To take one example, Tore Artelius has described the chain of action at the Iron Age cemetery close to Sannagård in Halland, Sweden (RÄ̈ 30). More than 130 burials were identified at this site. The mortuary tradition at this locale included cremation, post-cremation treatment of bones, ceremonial meals, destruction of ceramics, deposition of bones in the grave, and the construction of a small monument over the grave (Artelius 2000:206-213). Some of these actions were carried out in a special building, erected at the cemetery. In a sense, Artelius' study is an example of microarchaeology. By going into detail, discussing particular events and social situations at a single locale, he provides an explicit account of the chains of action that constitute 
mortuary practices. These 'chains of action' (structurating practices) are only valid for this particular locale. Subsequently, this particular set of action can be compared with other sites, and the extent of repetitiveness can be studied in detail. Some fibres (structurating practices) probably occur across large areas and time-spans, while other elements may be particular to the location in question.

At the site of Pichao, north-west Argentina, mentioned above, a large series of burials have been identified. There is a marked variation in funerary tradition over time. These changes have traditionally been explained only as the result of external contact and intrusion, related to the expansion of the Inca Empire and particularly to the arrival of the Spanish conquerors. Whether or not the external explanation model can account for the whole variability at the site is under question. An interesting way to study such articulations is to work at the local level, including local variability in social practice, which is often neglected in more general studies. A typical fibre of social practice at Pichao is a special type of burial, a cist with corbelled vault, which endures far into the period of contact with the Spaniards. But the depositions in the grave changes considerably in the period of contact. In general, new types of items are deposited, including some Spanish imported objects, notably metal and beads (Johansson 1996). Adding to this complex pattern are new types of ceramic vessels introduced during this period. These vessels neither reproduce Spanish ceramics nor build on older local traditions but rather can be characterised as a social innovation (Cornell \& Stenborg, ms.). What we can tell from the material record at this site is that some fibres remain intact (the grave type), while others change (e.g., ceramic types) in relation to the new social situation.

However, the burial practices at Pichao also occur in different contexts. During the pre-Hispanic period there are large cemeteries with a whole set of burials as well as some isolated buildings, probably related to the mortuary tradition. These cemeteries are situated in special areas of little use for terraced field agriculture, which was an important tradition at this locale. But during the same period there are also individual burials distributed across the landscape, burials in buildings, burials below walls of buildings, and burials in ceremonial cairns (Cornell \& Medina 2001). This wide range in the localisation of burials is interesting, and it indicates a complex social practice in relation to death. A systematic study of these burials could identify less evident fibres and bundles of fibres and enable an analysis of their distribution throughout the site. To give some examples, the internment of an adult man below the wall of a building is notable; and the internment of a small child in a ceramic vessel in a ceremonial cairn is not less notable. Apparently no objects were buried with the adult man, while the child was buried in a decorated ceramic vessel.

Thus, it is of little help to define a cemetery area a priori, before the social analysis. There may be special areas for burials, but this cannot be taken for granted, and the degree of true social diversity and difference cannot be defined prior to analysis. Rituals related to death may well be related to other sorts of social practice and to material constraints of great functional and symbolic significance. Keeping the analysis within the realms of a particular site does not, as suggested by Bradley, give a full picture of 
the mortuary practices conducted by the individuals inhabitating the area. But as previously argued, this is not the aim of microarchaeology. Fibres and threads extracted from such practices have to be related to other structurating practices at the site, and if necessary, the spatial realm of the analysis can be expanded with additional, carefully designed, small-scale analysis to support hypothetical fictions derived from the local information.

A promising approach is an analysis of the structuration of space, that is, the relations between material conditions ('natural' and 'cultural') and different activity areas. Here again, burials can be of particular interest, tracing the structurative practices involved in placing graves and cemeteries in the landscape. This kind of spatial analysis has traditionally been deployed from either a rationalist or a phenomenological perspective (cf. Zubrow 1994). But if analysed from an embodied perspective dialectically in relation to the properties of the specific local environment, such relations can provide interesting social information (Fahlander 2001:49-57; Cornell \& Fahlander 2002). For instance, excavations and a full-coverage survey conducted in the Asea Valley in Arcadia, Greece have identified archaeological evidence of a variety of activity areas, including a number of burials (Forsén, Forsén \& Lavento 1996). The burials in the area follow a standard practice well known from other parts of Greece. The graves are mainly typical stonelined cist-graves or tile-graves. These standard types follow approximately the same design, from prehistoric Helladic burials to those of the medieval period. What seems to differ chronologically is the location of the burials. In Asea some relations can be identified regarding the placing of the dead (fig. 2). For instance, the burials associated with the settlement of the central acropolis are situated relatively far off on the other side of the closest waters in the area. Here it seems that a particular aspect of the landscape was important enough for people to bother about transporting their dead about $800-1200 \mathrm{~m}$. There are suitable areas closer to the settlement, but not separated by water, which were not used. Later, in the Roman period (ca. first to early seventh century AD), that particular aspect seems suspended as the burials are placed closer to the settlements, often to the east and in association with roads. It is not possible in this connection to go into detail (for a more thorough analysis of the burials of Asea, see Fahlander ms.), but something can be said from these highly simplified examples. What we can tell from the spatial relations in the Asea Valley is that some fibres remain intact (the grave types), while the placing of burials changes in relation to other aspects of the socionatural environment. What these types of changes imply in terms of cosmology, ideology and suchlike is not obvious, but rather, is a question open for further analysis.

\section{SUMMARY}

This text outlines the basics of an operative social theory, suitable for archaeological materials and questions, which is not based on the idea of homogeneous social systems. We suggest that Sartre's concept of serial action provides an illustration of how the sociality of agency is directly related to the material world. This relationship seems to imply that social action mediates individual agency with structural patterns, that is, 


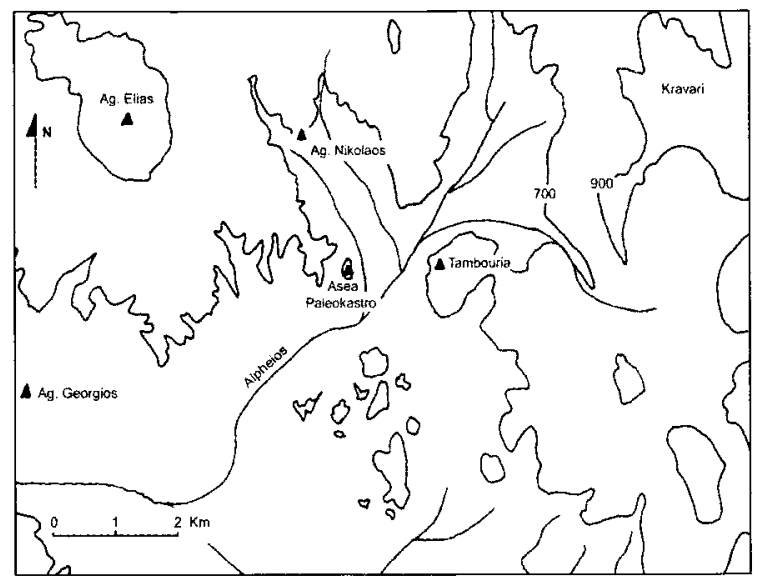

Fig 2. A map of the central part of the Asea Valley. The burials associated with the acropolis Paleokastro are situated at the NW slopes of Tambouria and around Agios Nikolaos.

the structures enabling or constraining human action. We do not favour any of the traditional dualist concepts like individualsociety, structure-agency, etc., since the relevance of such virtual concepts is dubious. The archaeological evidence (artefacts and other traces) provides, to varying degrees, information on structurating practices performed at a particular locale. The key element of the argument is the recognition of structurating practices, illustrated here by the metaphor of fibres (structurated practices) woven into threads and even ropes across time and space. At another level, social positivities constitute more durable, positive, aspects of materiality or sociability, which operate in the context of structurated practice. This type of microarchaeology is not simply a return to structuralism, even if such a perspective may help to elucidate the quantitative macro-oriented aspects of social life. An element of constructionism is necessary to prevent that the analysis exaggerate the homogeneous aspects of social agency and practice. It has not escaped our attention that the microarchaeological approach has great potential for small-scale rescue excavations.

\section{English revised by Laura Wrang.}

\section{REFERENCES}

Adorno, T. 1966. Negative Dialektik. Frankfurt am Main.

Alcock, S. 1993. Graecia capta. The landscapes of Roman Greece. Cambridge.

Andrén, A. 1997. Mellan ting och text. En introduktion till de historiska arkeologierna. Stockholm/Stehag. Archer, M. 1982. Morphogenesis versus structuration: on combining structure and action. British Journal of Sociology Vol 33, No 4. Pp. 455- 483.

Artelius, T. 2000. Bortglömda föreställningar. Begravningsritual och begravningsplats $i$ halländsk yngre järnålder. Gotarc series B: 15/ Raä Ark. und. 36, Göteborg.

Barrett, J. 1994. Fragments from Antiquity: an archaeology of social life in Britain, 2900-1200 BC. Oxford. Barrett, J. C. 2001, Agency, the duality of structure, and the problem of the archaeological record. In: Hodder, I. (Ed). Archaeological Theory Today. Pp.141-164, Cambridge.

Barth, F. 1992. Towards greater naturalism in conceptualizing societies. In: Kuper, A. (Ed). Conceptualizing Society. Pp. 17-33. London \& New York.

Bhaskar, R. 1993. Dialectics: the pulse of freedom. London \& New York. 
- 1994. Plato Etc. London \& New York.

Binford, L. 1971. Mortuary practices. Their study and potential. In: Brown, James A. (Ed). Approches to the social dimensions of mortuary practices. (Memoirs of the Society for American Archaeology no 25). American Antiquity vol 36, No 3, Part 2. Pp. 6-29.

- 1978. Nunamiut Ethnoarchaeology. New York.

- 1983. Working at Archaeology. New York.

Bourdieu, P. 1980. Le sens pratique. Paris.

Bradley, R. 1995. Trial and error in the study of mortuary practices - exploring the regional dimension. In: Anderson Beck, L. (Ed). Regional Approaches to Mortuary Analysis. Pp. v-ix. New York and London.

Braidotti, R. 1991. Patterns of Dissonance. A Study of Women in Contemporary Philosophy. Cambridge.

Butler, J. 1990; Gender Trouble, Feminism and the Subversion of Identity. New York.

- 1997. The Physic Life of Power. Theories in subjection. Stanford.

Clarke, D. L. 1968. Analytical Archaeology. London.

Collins, R. 1981. Micro-translation as a theory-building strategy. In: . Knorr-Cetina \& Cicourel (Eds). Advances in Social Theory and Methodology. Toward an integration of micro- and macro-sociologies. Pp. 81-108. Boston \& London.

Cornell, P. \& Stenborg, P. (ms.): Spanish Conquest, Ethnicity and Social Innovation: the case of the Santa Maria valley, NW Argentine.

Cornell, P. \& Fahlander, F. 2002. social praktik och stumma monument introduktion till mikroarkeologi. Gotarc serie C, Göteborg. (in press).

Cornell, P. \& Medina, M-C. 2001. El cuerpo como espacio social: notas sobre cadaveres públicos y privados. In: Medina, M-C (Ed). Lo publico y lo privado: género en America Latina. Pp. 193-211. Göteborg.

Cornell, P. 2000. Post-structuralism and 'Archaeology': Michel Foucault and Jacques Derrida. In: Holtorf, C. \& Karlsson, K. (Eds). Philosophy and Archaeological Practice. Perspectives for the 21 st Century. Pp. 173-184. Göteborg.

- 1993. Centres and the Household. Gotarc, Series C:6. Gothenburg.

Cornell, P. et al 2001. Prehispanic Settlement Organisation and Archaeological Analogy in the Santa María Valley; NW Argentina: Mapping the Pichao site. (in press).

Dobres, M-A. 2000. Technology and Social Agency. Outlining a Practice Framework for Archaeology. Oxford.

Fahlander, F. 2001. Archaeology as science fiction. A microarchaeology of the unknown. Gotarc serie C, no 43. Gothenburg.

- (ms): Mortuary Data: Structural Relations Between Burials, Settlements and the Landscape. In: Forsén, J. \& Forsén, B. (Eds). The Asea Valley Survey. An Arcadian Mountain Valley from the Palaeolithic Period until Modern Times, in press. Pp. 401-415.

Forsén, J., Forsén, B., \& Lavento, M. 1996. The Asea valley survey - a preliminary report of the 1994 season. Opuscula Atheniensia XXI:5. Pp.73-97. Göteborg.

Foucault, M. 1963[1994]. The Birth of the Clinic. An archaeology of medical perception. transl. A.M. Sheridan Smith. New York.

Gellner, E. 1995. Anthropology and Politics. Revolutions in the sacred grove. Oxford.

Gero, J. 2000. Troubled Travels in Agency and Feminism. In: Dobres \& Robb (Eds). Agency in Archaeology. Pp. 34-39. London \& New York

Giddens, A. 1984. The Constitution of Society. Outline of the Theory of Structuration. Cambridge.

Ginzburg, C. 1989. Clues, Myths, and the Historical Method. Translated by John and Anne C. Tedeschi. Baltimore.

Goffman, E. 1974. Frame Analysis. New York.

- 1967. Interaction Ritual. New York.

Graves-Brown, P.M. (Ed). 2000. Matter, Materiality, and Modern Culture. London.

Johansson, N. 1996. Burials and Society : a study of social differentiation at the site of El Pichao, northwestern Argentina, and in cemeteries dated to the Spanish native period. Gotarc, Series B: 5, Göteborg. 
Koerner, S. \& Gassón, R. 2001. Historical archaeology and new directions in environmental archaeology. Examples from Neolithic Scandinavia and Venezuela (400-1400 A.D.). In: Albarella (Ed). Environmental Archaeology: Meaning and Purpose. Pp. 177-210. Dordrect.

Kubler, G. 1962. The Shape of Time: Remarks on the History of Things. New Haven and London.

Lacan, J. 1972(1949). Spegelstadiet som utformare av jagets funktion. Psykologi i teori och praktik nr 4. Trans: Erik Graffman. Pp.38-46.

- 1988 [1978]. The seminar of Jacques Lacan. Book II. Ed: Jaques-Alain Millner. Cambridge.

Latour, B. 1992a. Aramis ou l'amour des techniques. Paris.

- 1992b. Where are the Missing Masses? The Sociology of a Few Mundane Artefacts. In: Bijker \& Law

(Ed). Shaping Technology/Building Society. Studies in Sociotechnical Change. Pp. 225-258. Cambridge.

- 1993a. We Have Never Been Modern. New York.

- 1993b. Ethnography of a "High-Tech"Case. About Aramis. Technological Choices. Transformations in Material Culture since the Neolithic. In: Lemonnier, P. (Ed). Pp. 372-398. London \& New York.

- 1999a. Pandoras Hope. Essays on the Reality of Science Studies. Cambridge.

- 1999b. On Recalling ANT. In: Law \& Hassard (Eds). Actor Network Theory and After. Pp. 15-25. Oxford.

Leach, E. 1989. Tribal ethnography: past, present, future. In: Tonkin, Donald \& Chapman (Eds). History and Ethnicity. Pp.34-47. London \& New York.

Levi, G. 1991. On Microhistory. In: Burke, P. (Ed). New Perspectives on Historical Writing. Pp. 93-113. Cambridge.

McIntosh, R. J., J. Tainter \& McIntosh, S. K. (Eds). 2000. The Way the Wind Blows. Climate, History, and Human Action. New York.

Molino, J. 1992. Archaeology and symbol systems. In: Gardin, J-C \& Peebles C. (Eds). Representations in Archaeology. Pp.15-29. Indianapolis.

Morris, I. 1987. Burial and Ancient Society. The rise of the Greek city-state. Cambridge.

Pader, E-J. 1982. Symbolism, Social Relations and the Interpretation of Mortuary Remains. British archaeological reports. International series 130 . Oxford.

Parker-Pearson, M. 1982. Mortuary practices, society and ideology: an ethnoarchaeological study. In: Hodder, I. (Ed). Symbolic and Structural Archaeology. Pp. 99-113. Cambridge.

Rathje, W. \& Cullen, M. 1992. Rubbish!: the archaeology of garbage. New York.

Renfrew, C. 1984. Approaches To Social Archaeology. Edinburgh.

Riggins. H. (Ed). 1994. The Socialness of Things: essays on the socio-semiotics of objects. Berlin.

Sartre, J-P. 1959 [1938]. Nausea. Transl: Lloyd Alelexander. New York.

- 1960. Critique de la raison dialectique. Paris.

Saxe, A. 1970. Social Dimensions of Mortuary Practices. Univ Microfilms. Ann Arbor.

Schiffer, M. B. 1999. The Material Life of Human Beings: artifacts, behavior, and communication. London.

Shanks, M. \& Tilley, C. 1987; Social Theory and Archaeology. Cambridge: Cambridge University Press.

Tilley, C. 1994. A Phenomenology of Landscape. Oxford.

Wittgenstein, L. 1953. Philosophical Investigations, Oxford.

Young, I. M. 1997. Intersecting Voices: Dilemmas of Gender, Political Philosophy and Policy. Princeton. Zizek, S. 1989. The Sublime Object of Ideology. London \& New York.

- 1999. The Ticklish Subject: the absent centre of political ontology. London \& New York.

Zubrow, E. 1994. Knowledge representation and archaeology: a cognitive example using GIS. In: Renfrew,

Colin \& Zubrow, Ezra (Eds). The Ancient Mind. Elements of cognitive archaeology. Cambridge.

Orskov, W. 1966. Aflcesning av objekter. København.

- 1972. Objekterne. København. 